\title{
LÍNGUA PORTUGUESA COMO PASSAPORTE PARA A CIDADANIA: ESTUDO DE CASO COM IMIGRANTES HAITIANOS NO IFRS - CAMPUS BENTO GONÇALVES
}

\author{
PORTUGUESE LANGUAGE AS A WAY THROUGH CITIZENSHIP: A \\ CASE STUDY WITH HAITIAN IMMIGRANTS AT IFRS-CAMPUS BENTO \\ GONÇALVES
}

\author{
Carina Fior Postingher Balzan ${ }^{1}$ \\ Leandro Rocha Vieira ${ }^{2}$ \\ Júlia Sonaglio Pedrassani ${ }^{3}$
}

\section{Resumo}

O artigo aborda o ensino da língua portuguesa para imigrantes haitianos desenvolvido no Curso de Extensão para imigrantes e refugiados do IFRS-Campus Bento Gonçalves. A abordagem teórica que ampara a proposta metodológica do curso é a de língua de acolhimento, dada a condição desses sujeitos, que chegam em situação de vulnerabilidade social, geralmente com pouquíssimos recursos financeiros e desgastados pelo processo migratório, agravado, ainda, pelo rompimento dos laços familiares, linguísticos e culturais. A pesquisa, de caráter exploratório, realizou um estudo de caso com os participantes do Curso, com aplicação de questionário, em que se buscou traçar o perfil sociocultural do grupo investigado. Os resultados permitem conhecer melhor os imigrantes, suas reais necessidades em relação à língua portuguesa, e auxiliam no delineamento de metodologias de ensino e materiais didáticos apropriados à turma, tornando o processo de ensino e de aprendizagem mais significativo e contribuindo, assim, para a integração social deles.

\section{Palavras-Chave}

Imigrantes e refugiados. Língua portuguesa. Língua de acolhimento.

\begin{abstract}
The article approaches the teaching of Portuguese language for Haitian immigrants developed in the Extension Course for immigrants and refugees of IFRS-Campus Bento Gonçalves. The course methodological proposal is based on a theorical approach that takes Portuguese as a Host Language due to these subjects' situation, who arrive in a social vulnerability condition, usually with low financial resources and worn out by the migratory process, worsen by the break of family, linguistic and cultural ties. This exploratory research carried out a case study with the Course students, in which a form was applied in order to chart the investigated group's sociocultural profile. With the results it was possible to know the immigrants better and their real needs in relation to Portuguese language. The results also contributed to set out teaching methodologies and appropriated didactic material to the group, making the teaching-learning process more significative and therefore contributing to the social integration process.
\end{abstract}

\section{KEYWORDS}

Immigrants and refugees. Portuguese Language. Host language.

\footnotetext{
1 Doutora em Letras pela Universidade de Caxias do Sul. Docente do IFRS - Campus Bento Gonçalves. Coordenadora do Projeto de Extensão Língua Portuguesa para imigrantes e refugiados.

2 Mestre em Letras e Cultura pela Universidade de Caxias do Sul. Técnico em assuntos educacionais do IFRS - Campus Bento Gonçalves.

3 Graduanda do Curso de Licenciatura em Letras do IFRS - Campus Bento Gonçalves. Bolsista de Iniciação Científica.
} 


\section{INTRODUÇÃo}

Os processos migratórios são movimentos populacionais que ocorrem no mundo inteiro, por diferentes motivos. O Brasil foi formado a partir desse fenômeno de mobilidade, afinal, sua população foi constituída, preponderantemente, a partir de imigrações que vêm ocorrendo desde o período Colonial, processo que ganhou força a partir do século XIX, quando o país recebeu levas significativas de europeus (ZAMBERLAN et. al., 2014) e, atualmente, é o principal destino de pessoas de diversas nacionalidades.

Desde 2010, os protagonistas da imigração no Brasil têm sido os haitianos, que deixam sua pátria em busca de melhores condições de vida. Segundo pesquisa de Uebel (2014), no ano de 2000, não havia nenhum haitiano registrado no país; já em 2010, eram 175; e, em 2014, o número subiu para mais de 20.000 pessoas. Deve-se levar em consideração, no entanto, a possibilidade de existir uma parcela de imigrantes ilegais, o que permite que esse número seja ainda maior. Ainda, de acordo com Uebel (2014), no Rio Grande do Sul, em 2010, não havia nenhum registro dessa imigração e, em 2014, já eram 2.517 pessoas, sendo que no município de Bento Gonçalves, localizado na Serra Gaúcha, estimava-se que, em 2018, havia cerca de mil imigrantes haitianos. De acordo com dados fornecidos pela Secretaria Municipal de Habitação e Assistência Social, em 2019, há 671 imigrantes haitianos que, juntamente com seus familiares, utilizam os benefícios do Cadastro Único ${ }^{4}$. Ainda assim, deve-se considerar que não são todos que acessam os serviços da assistência social, o que pode elevar o número de haitianos residentes no município.

O motivo do aumento desta imigração vinda do Haiti deve-se ao fato desse país ter sido atingido por catástrofes naturais e por guerras há mais de uma década, ou seja, pela população viver em uma constante crise humanitária. Em 2004, o país quase enfrentou uma guerra civil, dissuadida pela intervenção da Organização das Nações Unidas (ONU); em 2010, foi atingido por um terremoto, que dizimou mais de 300 mil pessoas, seguido de uma epidemia de cólera e, na sequência, em 2012, um tsunami devastou o país. Os desastres que atingiram o Haiti desencadearam alterações demográficas e econômicas, principalmente, em relação à agricultura. De acordo com Zamberlan et. al. (2014), o terremoto acelerou o processo de êxodo rural, direcionando a população para a capital, Porto Príncipe, onde, em 2014, já viviam cerca de 2,5 milhões de pessoas. Essa sequência de fatos foi determinante para fazer com que um grande número de haitianos deixasse a terra natal à procura de melhores oportunidades para recomeçar a vida.

É importante aqui fazer a distinção entre imigrantes e refugiados, uma vez que a adoção desses termos traz consequências legais e práticas em relação a cada uma dessas condições. Segundo Zamberlan et. al. (2014), por imigrante entende-se a pessoa que entra e se estabelece em alguma região, mas enquanto está em movimento é considerada migrante. Refugiado é quem é forçado a sair de seu país de origem por ter seus direitos humanos violados. De acordo com São Bernardo (2016), a imigração pode ser forçada por motivos como guerra, perseguições ideológicas ou étnicas e por desastres naturais. A situação de refúgio é concedida em todos esses casos, exceto quando o motivo da migração é causado por desastres naturais.

4 O Cadastro Único para Programas Sociais, vinculado à Assistência Social, é um banco de dados que identifica e caracteriza famílias de baixa renda (famílias com renda mensal de até 03 salários mínimos ou 1/2 salário mínimo per capita) para potencial acesso a programas sociais. 
Em razão disso, ao chegarem ao Brasil, os haitianos são considerados, pela legislação, imigrantes e não refugiados, sendo que, em 2012, criou-se um visto humanitário, concedido a eles a fim de diminuir a burocracia exigida para ingressarem no país. Todavia, essa não se constitui na única medida em termos de inovação legal. Anteriormente a esse visto, a Lei no 9. 474, de 1997, que criou o Comitê Nacional para os Refugiados (CONARE), facilitou a emissão de documentos, como Cadastro de Pessoa Física (CPF) e carteira de trabalho, e garantiu os direitos cíveis do imigrante (BRASIL, 1997). Esse processo, ao mesmo tempo em que facilitou a entrada de imigrantes haitianos no Brasil, foi relevante para motivar a saída deles do país de origem. Para Zamberlan et. al. (2014), outros motivos de atração também colaboraram para que o destino dos imigrantes fosse o Brasil. Alguns deles foram os recursos investidos no Haiti, depois do terremoto de 2010, que incluem cerca de 40 projetos em diversas áreas, como agricultura, alimentação, formação profissional, saúde, educação, desenvolvimento urbano, etc. Diversas instituições brasileiras empenharam-se nessa missão, como a EMBRAPA, o SENAI, o SENAC e alguns órgãos federais, como o Ministério da Justiça, da Saúde e da Educação, o que criou uma imagem positiva do Brasil perante o povo haitiano. Organizações não governamentais (ONGs) e igrejas também tiveram papel importante para a reconstrução do país e para melhorar a condição de vida da população. Ainda há outros fatores, como as possibilidades de emprego oferecidas em algumas regiões brasileiras, a declaração de apoio humanitário por parte do poder público, bem como a promessa de acolhimento àqueles que desejassem emigrar para o Brasil.

Para Ubel e Rückert (2018, p. 101), “a presença dos haitianos no Rio Grande do Sul é justificada pela oportunidade de emprego em posições não mais desejadas pelos próprios sul-riograndenses". Eles direcionaram-se à região da Serra Gaúcha por ser mais desenvolvida economicamente do que as outras regiões do Estado, sendo que Bento Gonçalves e Caxias do Sul receberam mais de 50\% dessa imigração. De acordo com Zamberlan et. al. (2014), com base nos dados do relatório de 2013 da missão Scalabriniana, em Manaus, os setores que mais contratam os imigrantes são os relacionados à indústria alimentícia, como a de frigoríficos, seguido pelo setor de serviços, como o da construção civil. Conseguir um trabalho é uma necessidade urgente para esses sujeitos, o que lhes possibilita sobreviver no novo país e, assim que possível, enviar remessas de dinheiro aos familiares que ficaram no Haiti e, em alguns casos, ainda pagar as dívidas que foram contraídas em razão da imigração.

A inserção no mercado de trabalho, bem como nas comunidades em que vivem, entretanto, é um desafio a ser enfrentado por essas pessoas. Zamberlan et. al. (2014) afirmam que quando o imigrante sai do seu país de origem, ele se distancia de suas raízes, e quando chega no novo destino a falta do convívio com seus familiares e amigos faz com que a vida se torne mais difícil, pois não é fácil criar outros vínculos e permanecer emocionalmente estável. Nesse caso, a principal ajuda vem das instituições humanitárias, como igrejas e ONGs, que se preocupam com a acolhida dessas pessoas e com a integração delas na comunidade, integração essa que, com certeza, passa pela aprendizagem da língua portuguesa. No entanto, alguns pesquisadores acreditam que esse papel de integração social deveria ser cumprido pelo poder público, pois como sustentam Zamberlan et. al. (2014, p. 37), “esse processo imigratório mostrou o anacronismo da própria política brasileira de 
imigração. Mostrou as desavenças entre os poderes constituídos - municipal, estadual e federal vivendo um jogo de empurra-empurra, um acusando o outro e todos lavando as mãos".

Essa falta de institucionalização de políticas públicas a imigrantes influi em outra necessidade de extrema importância para eles, que ainda é pouco contemplada, o ensino de língua portuguesa para imigrantes e refugiados. De acordo com Zamberlan et. al. (2014), a oferta dos cursos de língua portuguesa tem sido realizada, principalmente, por instituições humanitárias que se sensibilizam com os imigrantes e buscam auxiliá-los no processo de integração social. Esses cursos, geralmente, ministrados por voluntários quase sempre sem formação na área, não deixam de ser significativos para um primeiro contato com a língua portuguesa, porém, desprovidos de uma metodologia adequada e de material didático apropriado, acabam não cumprindo seu objetivo. As aulas ocorrem, usualmente, depois do período de trabalho, quando os imigrantes estão cansados, o que prejudica a aprendizagem. Outros fatores também atrapalham a aprendizagem da língua, como o pouco tempo para o estudo e a falta da prática em situações comunicativas com falantes nativos, já que, entre si, os haitianos acabam utilizando a língua materna de origem, o crioulo haitiano (kreyòl ayisyen).

Pensando nessas situações é que o Instituto Federal de Educação, Ciência e Tecnologia do Rio Grande do Sul (IFRS) - Campus Bento Gonçalves, como instituição pública e gratuita, atenta às demandas regionais e consciente de seu papel social, passou a desenvolver, desde o ano de 2013, ações de extensão de língua portuguesa para imigrantes e refugiados com vistas a auxiliá-los no processo de integração social. O presente artigo, portanto, aborda o ensino de língua portuguesa desenvolvido no Curso de Extensão Língua Portuguesa para imigrantes e refugiados no IFRS-Campus Bento Gonçalves ${ }^{5}$, sob a perspectiva de língua de acolhimento. Além de uma pesquisa bibliográfica sobre o ensino de língua não materna, foi realizado um estudo de caso a fim de obter dados socioculturais dos imigrantes haitianos ${ }^{6}$ participantes do Curso, os quais permitem traçar um perfil da turma ao mesmo tempo que auxiliam os docentes na definição de metodologias e elaboração de materiais didáticos adequados às reais necessidades do grupo.

Acredita-se que o conhecimento sobre aspectos familiares, da formação escolar, do mundo do trabalho, da religião, entre outros, seja fundamental para que o processo de ensino e de aprendizagem seja mais significativo para o grupo, uma vez que permite aos docentes conhecer as reais necessidades dos imigrantes, trazendo para a sala de aula situações comunicativas reais de interação social que os sujeitos vivenciam em seu cotidiano.

\section{LínguA PORTUGUeSA COMO LÍNGUA De ACOLHimento}

O conhecimento da língua oficial do país em que se encontra é fundamental para que o imigrante consiga estabelecer-se em uma nova comunidade e realize atividades básicas, como pedir informações, deslocar-se pela cidade, procurar emprego, ter acesso a serviços públicos, buscar atendimento médico, etc.

\footnotetext{
5 O presente artigo está vinculado ao Projeto de Pesquisa intitulado "Língua portuguesa como passaporte para a cidadania: aspectos socioculturais e linguísticos dos participantes do Curso de Extensão Língua Portuguesa para imigrantes e refugiados do IFRSCampus Bento Gonçalves". Como a pesquisa envolve seres humanos, obedecendo à Resolução n.466/2012, do Conselho Nacional de Saúde, o projeto de pesquisa foi submetido e aprovado pelo Comitê de Ética em Pesquisa do IFRS. A pesquisa é executada com recursos do Edital IFRS no 77/2018 - Fomento Interno, vinculado ao Edital no 51/2018 - Campus Bento Gonçalves.

6 Os imigrantes haitianos constituem a grande maioria do público que frequenta o Curso de Extensão de Língua Portuguesa, por esse motivo, optou-se em pesquisar apenas essa nacionalidade. No entanto, existem alunos de outros países nas turmas, como do Paquistão, Iraque, Bangladesh, México, República Dominicana e Venezuela.
} 
No caso dos imigrantes, a aprendizagem da língua portuguesa ocorre, principalmente, pela interação com os falantes nativos do idioma. De acordo com Grosso (2010), essa interação é tão importante quanto os conhecimentos da língua oficial, porque é através da interação que o aprendente começa a ter consciência não só do idioma, mas também da cultura e, por fim, a entender como os nativos utilizam a língua. Conforme São Bernardo (2016, p. 19), o conhecimento da língua "gera maior igualdade de oportunidades para todos, facilita o exercício da cidadania e potencializa experiências enriquecedoras[...]”. Esta autora postula que, diferentemente das crianças imigrantes que frequentam a escola diariamente e aprendem o idioma na interação com os colegas brasileiros, os adultos não têm essa mesma possibilidade. Eles também podem aprender por interação, mas levam mais tempo, o que faz com que tenham maior dificuldade para se inserirem na sociedade.

Assim, os imigrantes adultos são os que mais necessitam de oportunidades para aprenderem a língua portuguesa já que, ao chegarem no país de acolhimento, precisam agir de maneira independente, em um contexto diferente do que estavam acostumados no seu país de origem, especialmente no que tange às questões do mundo do trabalho (GROSSO, 2010). Surge, então, a necessidade da oferta de cursos de língua portuguesa para essas pessoas e, com isso, discussões relacionadas ao processo de ensino e de aprendizagem da língua em termos de metodologias (estratégias) mais adequadas a esse fim, de modo que os imigrantes consigam, a partir da língua, alcançar seus objetivos e integrar-se progressivamente à sociedade.

O ensino de Português como língua não materna é recente, e pode ser remetido ao ensino de português como língua estrangeira (LE), com pouco mais de 50 anos no Brasil, tendo como marco a publicação do livro Português para Estrangeiros, de Mercedes Marchand, em 1957 (SÃO BERNARDO, 2016). Desde então, os avanços na educação foram consideráveis, e novas abordagens de ensino de língua não nativa foram desenvolvidas. Grosso (2010, p. 63) define língua estrangeira como a "língua não nativa do sujeito por ele aprendida com maior ou menor grau de eficiência" e que se opõe à língua segunda, que a autora conceitua como a língua de escolarização "que contribui para o desenvolvimento psicocognitivo da criança num contexto em que a língua-alvo é a oficial" (GROSSO, 2010, p. 64). A língua segunda (L2) também pode ser definida como aquela que o falante mais domina depois da sua língua materna.

Stern (1983) diferencia o ensino de língua segunda do ensino de língua estrangeira, sendo que a primeira ocorre quando a língua é ensinada para não falantes do idioma em um ambiente em que esse é utilizado, sendo normalmente a língua oficial do país. Esse é o caso dos imigrantes que vêm para o Brasil e aprendem a língua portuguesa em situação de imersão linguística e cultural. Já o ensino de língua estrangeira ocorre quando a língua é ensinada em um ambiente em que o idioma-alvo não é utilizado. No contexto imigratório, por exemplo, o português seria ensinado como língua estrangeira se os imigrantes aprendessem o idioma ainda no país de origem. São Bernardo (2016) completa essa ideia ao afirmar que o conceito de língua portuguesa como língua segunda está também relacionado ao ambiente de imersão em que o aprendente se encontra, o que influencia o processo de ensino e de aprendizagem.

Complementarmente ao conceito de língua estrangeira e de língua segunda, o ensino de um idioma para imigrantes e refugiados pode apoiar-se em uma abordagem que o entenda como uma língua de acolhimento. Apesar de o Brasil ser, historicamente, um país formado por imigrantes, 
não existem, até o momento, políticas públicas para o ensino de língua portuguesa para imigrantes e refugiados. De acordo com Amado (2014), há um grande vácuo no ensino de português como língua de acolhimento para os estrangeiros que chegam ao Brasil em situação de miséria moral e, muitas vezes, com pouquíssimos recursos financeiros. Como explica a autora:

O ensino de português como língua estrangeira (PLE) no Brasil tem apresentado um crescente movimento nas últimas décadas, com a criação de cursos de PLE em escolas de idiomas e de cursos de extensão à comunidade acadêmica nas universidades. Os primeiros, contudo, voltam-se, majoritariamente, a um público de trabalhadores de grandes empresas e suas famílias; já os últimos prestam um serviço para alunos intercambistas e professores visitantes que, via de regra, permanecem de um a dois anos no Brasil. Há também os cursos voltados aos turistas que chegam ao país para os eventos do cenário esportivo, a Copa de 2014 e as Olimpíadas de 2016. São, portanto, públicos com necessidades específicas de aprendizado nos contextos em que se comunicarão em português (AMADO, 2014, p. 6).

O público a que esses cursos de PLE são destinados, ainda segundo Amado (2014), não contempla as milhares de pessoas que são forçadas a deixar seu país de origem para recomeçarem a vida no Brasil, talvez para nunca mais retornarem. Nesse sentido, ganha destaque o ensino de língua portuguesa como língua de acolhimento para esses estrangeiros que, dada a condição de imigrantes ou refugiados, chegam em situação de vulnerabilidade social, geralmente com pouquíssimos recursos financeiros e desgastados pelo processo migratório, agravado ainda mais pelo rompimento dos laços familiares, linguísticos e culturais.

São Bernardo (2016, p. 65) afirma que essa noção da língua vai além do ensino como língua estrangeira ou como língua segunda, abrangendo mais que conhecimentos linguísticos. Ela concebe o imigrante em um sujeito atuante na sociedade, "pois relaciona o uso da língua portuguesa a um conjunto de saberes, como saber agir, saber fazer novas tarefas linguístico-comunicativas que devem ser realizadas nessa língua, bem como a possibilidade de tornar-se cidadão desse lugar, cultural e politicamente consciente [...]".

Aprender a língua portuguesa e comunicar-se é, de acordo com São Bernardo (2016), o objetivo dos imigrantes. Eles pretendem, através da língua, ser inseridos na sociedade, sentir-se pertencentes ao novo país. Para Grosso (2010, p. 71), o ensino da língua de acolhimento "permite o acesso mais rápido à cidadania como um direito [...]".

Parte-se, assim, da ideia de que somente o domínio proficiente da língua de acolhimento possa dar condição plena de cidadania aos imigrantes, tornando-os sujeitos ativos na sociedade, capazes de requerer seus direitos e assumir suas responsabilidades, uma vez que a língua é fator de inserção individual e coletiva, de constituição da própria subjetividade. De acordo com Benveniste (1995), é o ato de fala, em uma dinâmica de troca, que instaura a experiência humana inscrita na linguagem. E é justamente essa inter-relação entre os sujeitos que está na base do princípio de subjetividade:

Não atingimos nunca o homem separado da linguagem e não o vemos nunca inventando-a. Não atingimos jamais o homem reduzido a si mesmo e procurando conceber a existência do outro. É um homem falando que encontramos no mundo, um homem falando com outro homem, e a linguagem ensina a própria definição do homem (BENVENISTE, 1995, p. 285). 
Dessa maneira, os conteúdos trabalhados com os imigrantes no ensino de Português como língua de acolhimento estão ligados a assuntos que mostrem o cotidiano em que eles passam a viver em situação de contato com a língua e a cultura alvo, que tratem de situações profissionais, culturais, interpessoais etc., e que as atividades sejam baseadas em situações-problema (GROSSO, 2010). Ainda de acordo ainda com Grosso (2010), a língua de acolhimento garante um importante elo afetivo entre o professor e o aluno, que se transforma em uma forma de interação linguística para o imigrante.

A relação entre docentes brasileiros e discentes estrangeiros serve como motivação para desenvolver uma metodologia de ensino adequada à situação em que os alunos se encontram e que atenda às suas necessidades para se estabelecerem na sociedade (SÃO BERNARDO, 2016). A autora afirma, também, que temas que envolvem a realidade dos alunos auxiliam o aprendizado, pois os aproximam e fazem com que eles usem a língua para contar sua própria história.

Entretanto, ainda existe uma lacuna neste tipo de ensino: a falta de material didático apropriado. De acordo com Grosso (2010, p. 69), “[...] o material didático utilizado para esse curso deveria ser construído a partir das necessidades e objetivos do grupo, os quais são muito específicos”, devendo basear-se na língua em uso. Para a elaboração do material em questão, Leffa (2003, p. 15 apud SÃO BERNARDO, 2016) estabelece algumas etapas importantes: a análise, que observa a necessidade dos alunos e suas características; o desenvolvimento, que direciona as atividades e os conteúdos de acordo com o que foi estabelecido na etapa anterior; a implementação, que é a aplicação do material elaborado; e a avaliação, que é realizada de maneira formal ou informal, a fim de verificar o nível de proficiência linguística do aluno e seus avanços na aprendizagem do português. A variação linguística deve ser contemplada nesse planejamento, de modo que os imigrantes consigam associar o que aprendem com o que vivenciam fora da sala de aula.

Complementando os aspectos mencionados anteriormente, outro elemento de fundamental importância para os estudos do ensino da língua portuguesa como língua de acolhimento é o próprio aluno, ou seja, o imigrante. Fatores variantes que envolvem o imigrante aprendiz de Português devem ser levados em conta no planejamento e desenvolvimento da aula, como a variação de conhecimento da língua do país em que ingressam; o nível de conhecimento da língua materna, que influencia o aprendizado do idioma novo; o conhecimento de outras línguas; e a situação socioeconômica em que o aluno se encontra (GROSSO, 2010). Esses aspectos podem representar um desafio ao docente dentro de uma mesma sala de aula.

\section{O CURSO de EXTENSÃo língua PORTUguesa PARA IMigRANTES E REFUgiados Do IFRS - CAMpus Bento Gonçalves}

A imigração haitiana no Brasil intensificou-se a partir de 2010. Uma parcela significativa desses imigrantes direcionou-se ao Rio Grande do Sul, mais especificamente à Serra Gaúcha. Esta região, de acordo com Ubel e Rückert (2018), por seu considerável desenvolvimento econômico, recebeu mais de 50\% da imigração haitiana do Estado. Ao chegarem nos municípios, depois de se estabelecerem com familiares ou conhecidos que já residiam aqui, esses imigrantes imediatamente buscam trabalho a fim de garantirem sua sobrevivência, mas também passam a buscar serviços públicos como assistência social, saúde e educação. Para realizar essas atividades, falar o idioma local é uma das prioridades desses indivíduos. No município de Bento Gonçalves, onde foi realizada a pesquisa, o IFRS é a única instituição pública a desenvolver cursos formais de ensino de língua por- 
tuguesa específicos para esse público. As ações ocorrem desde o ano de 2013, mas no ano de 2018, o Curso de Extensão foi reformulado, assumindo a perspectiva teórica de língua de acolhimento e passando a adotar uma nova metodologia de ensino.

O objetivo do Curso de Extensão é promover um aprendizado da língua portuguesa que permita aos sujeitos comunicar-se em situações cotidianas de interação social como: apresentar-se, pedir informações, locomover-se pela cidade, fazer compras, procurar emprego, providenciar documentação, ter atendimento médico, ler e compreender textos que circulam socialmente. A Instituição oferece duas turmas de nível básico, organizadas em Módulo 1 e Módulo 2. O primeiro módulo prioriza conhecimentos elementares da língua portuguesa que permitam a comunicação oral dos sujeitos em situações cotidianas de interação; já no Módulo 2, o conhecimento da língua escrita é aprofundado a partir de leitura e compreensão de textos de diferentes gêneros que circulam socialmente, além da produção escrita de pequenos textos, observando as normas gramaticais da língua portuguesa. Cada módulo tem carga horária de 30 horas, com duração de um semestre. As aulas ocorrem semanalmente, no turno da noite, com duração de 1 hora e 30 minutos, sendo ministradas por docentes da área de Letras, com experiência no ensino de língua portuguesa para estrangeiros. A avaliação ocorre pela participação e interesse nas atividades propostas e através do acompanhamento individual das habilidades comunicativas dos participantes.

O ingresso no Curso de Extensão dá-se a partir de chamamento público, após ampla divulgação entre associações de imigrantes da região, como também em órgãos públicos como as Secretarias de Assistência Social e de Educação do município de Bento Gonçalves. No caso de o número de interessados ser superior ao número de vagas ofertadas, é realizado um sorteio entre os presentes, e organizada uma lista de espera entre os que não foram contemplados, para que sejam chamados para comporem uma próxima turma. Ao final do Curso, os estudantes recebem um certificado de conclusão, sendo essa certificação um fator também relevante para o ingresso no mercado de trabalho.

Além disso, o Ministério da Justiça e Segurança Pública, por meio da Portaria Interministerial $\mathrm{n}^{\mathrm{o}} 16$, de 03 de outubro de 2018, que altera a Portaria Interministerial $\mathrm{n}^{\circ} 5$, de 27 de fevereiro de 2018 e a Portaria Interministerial no 11, de 3 de maio de 2018, em relação à flexibilização das regras sobre comunicação em português para fins de naturalização, tem exigido como documentação para a solicitação de naturalização brasileira para estrangeiros:

[...] d) conclusão de curso de idioma português direcionado a imigrantes realizado em instituição de ensino superior reconhecida pelo Ministério da Educação; ou e) aprovação em avaliação da capacidade de comunicação em língua portuguesa aplicado por instituição de ensino superior reconhecida pelo Ministério da Educação na qual seja oferecido curso de idioma mencionado na alínea "d"; (POLÍCIA FEDERAL, 2019).

A exigência dessa documentação pela Polícia Federal tem motivado um número considerável de imigrantes haitianos que residem no Brasil há alguns anos e que já possuem um bom domínio da língua portuguesa a procurarem esse Curso do IFRS com o objetivo de obterem a certificação, uma vez que a oferta, pública e gratuita, atende à demanda de imigrantes e de refugiados ávidos por integrar-se à sociedade brasileira por meio do domínio básico da língua, mas que não possuem recursos financeiros para custear seus estudos em uma instituição privada. 
Baseada na perspectiva teórica de língua de acolhimento, a proposta metodológica do curso prioriza, inicialmente, a expressão oral, através da conversação e interação entre professor e alunos, e os conteúdos desenvolvidos atendem às necessidades comunicativas manifestadas pelo próprio grupo ao longo das aulas. Apesar de se conhecer e de se pesquisar alguns materiais de base como a apostila "Pode Entrar: Português do Brasil para refugiados e refugiadas", de 2015, desenvolvida pela UNHCR/ACNUR (Agência da ONU para refugiados), em parceria com outros órgãos de apoio a imigrantes, e apostilas de outras instituições federais que trabalham com o ensino de língua portuguesa nesse contexto, os docentes do IFRS-Campus Bento Gonçalves desenvolvem o próprio material didático de acordo com as necessidades levantadas pelas turmas.

Entre as demandas principais dos imigrantes estão questões práticas do dia a dia, como apresentar-se em uma entrevista de trabalho, preencher uma ficha de emprego ou curriculum vitae, buscar atendimento médico, explicando seu estado de saúde, realizar compras no supermercado e na farmácia, etc. Mas também apresentam curiosidade em relação a aspectos socioculturais e geográficos do Brasil e do Rio Grande do Sul, demonstrando interesse pela história, geografia, culinária, religião, costumes, tradições e expressões linguísticas do povo brasileiro. Além disso, os imigrantes apresentam grande necessidade de conhecer a morfologia, principalmente verbos, e a sintaxe da língua portuguesa a fim de conseguirem se expressar com correção e serem compreendidos quando conversam com os brasileiros. Ao ouvir e atender as demandas dos imigrantes, a aula torna-se muito dinâmica, a interação entre os alunos e os docentes faz com que os imigrantes se tornem realmente protagonistas de sua aprendizagem, sentindo-se valorizados em suas necessidades e acolhidos pela Instituição.

Resultado disso pode ser constatado no baixo índice de desistências e evasão, que varia em torno de $10 \%$ do número total de alunos. Entre esse percentual estão algumas pessoas que não conseguiram mais frequentar o Curso por terem conseguido um emprego à noite, mesmo turno das aulas. Cabe mencionar, ainda, dois momentos bastante significativos no Curso: o primeiro é a confraternização de encerramento do semestre, que ocorre com a integração das duas turmas, momento de escuta desses sujeitos, em que podem falar da importância do curso e do aprendizado da língua portuguesa em suas vidas e sobre o que pode ser melhorado para as turmas vindouras, contribuindo para o aperfeiçoamento dessa ação; e o segundo, a entrega dos certificados de conclusão. Nesses momentos de descontração, evidencia-se o quanto esses imigrantes se sentem à vontade na Instituição, como se sentem pertencentes à comunidade escolar, usufruindo de um espaço em que são realmente respeitados e valorizados enquanto sujeitos e cidadãos.

Nesse sentido, assumindo-se a proposta metodológica de ensino do Português como língua de acolhimento, e visando-se estratégias mais assertivas de ensino da língua, torna-se necessário investigar melhor o perfil desses estudantes, conhecer suas condições sociais e econômicas, suas perspectivas de vida no novo país, as dificuldades encontradas na interação social, e, principalmente, se a aprendizagem da língua portuguesa vivenciada no Curso de Extensão tem auxiliado a comunicação, trazendo resultados positivos no processo de integração social.

\section{Perfil sociocultural dos imigrantes haitianos no IFRS - campus Bento GonçAlves}

A pesquisa, de caráter exploratório, realizou um estudo de caso com os participantes do Curso de Extensão Língua Portuguesa para imigrantes e refugiados do IFRS-Campus Bento Gonçal- 
ves, com aplicação de questionário, com questões abertas e fechadas tendo por finalidade conhecer o perfil do aluno desse Curso. No dia da aplicação do questionário, o Termo de Consentimento Livre e Esclarecido (TCLE) foi lido e explicado aos sujeitos, que o assinaram aceitando participar da pesquisa, e ficaram com uma cópia do documento. Responderam ao questionário dezenove alunos haitianos, que estavam finalizando o Módulo 2, em julho de 2019. O questionário foi aplicado pela pesquisadora e docente da turma, que auxiliou os sujeitos que apresentaram dúvidas em relação às perguntas. Mesmo assim, cabe mencionar que algumas questões não foram respondidas pelos participantes. A partir das respostas fornecidas pelos alunos, pôde-se traçar seu perfil sociocultural, no que diz respeito a aspectos como constituição familiar, formação escolar, trabalho e renda, religião, motivos que os levaram a emigrar, além de verificar se o aprendizado do idioma contribuiu para o processo de socialização na comunidade.

O ano de chegada desses imigrantes ao Brasil varia entre 2008 e 2018, como mostra o Gráfico 01.

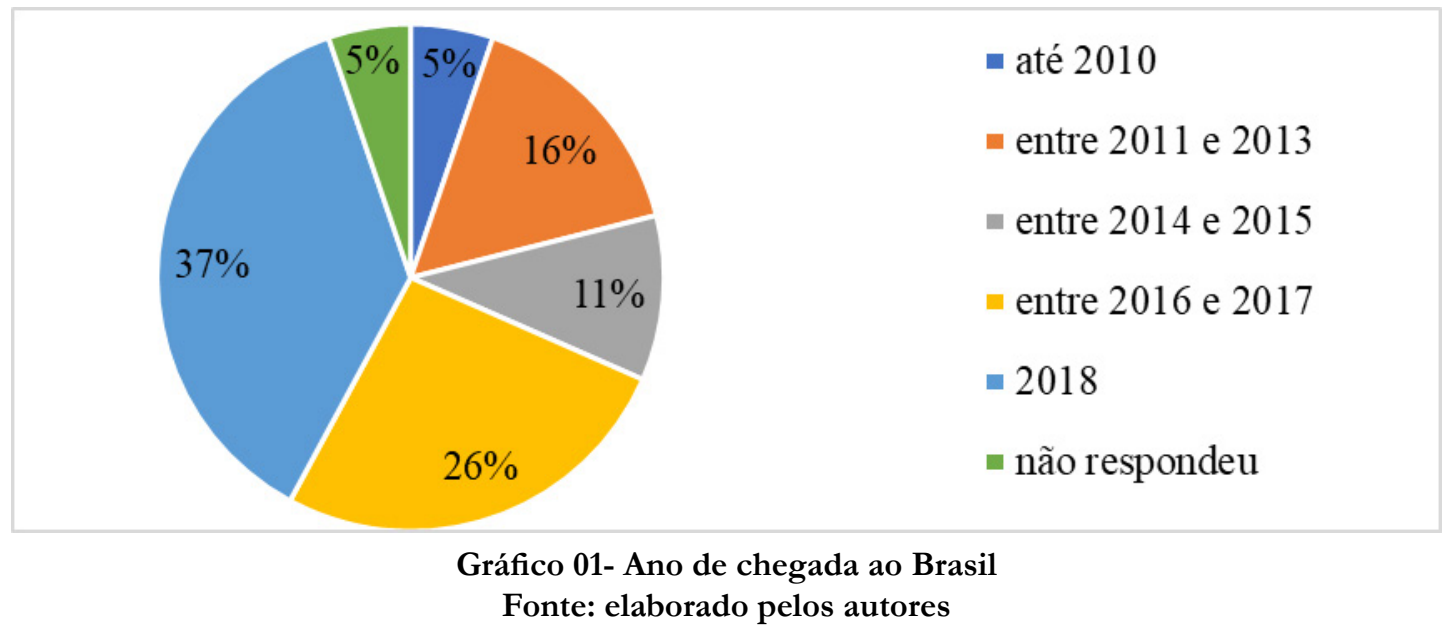

Apenas 5\% dos imigrantes haitianos chegaram antes de 2010; 16\% chegaram entre 2011 e 2013; 11\%, entre 2014 e 2015; 26\%, entre 2016 e 2017; e 37\% em 2018, ano em que iniciaram o curso; $5 \%$ não responderam à questão. Estes dados mostram que a frequência de imigração de haitianos para o Brasil tem aumentado nos últimos anos, principalmente após 2016, e corroboram as observações feitas por Uebel e Rückert (2018), que apontam duas ondas migratórias de haitianos que chegaram ao Brasil. A primeira após o terremoto de 2010 que:

[...] não tinha como destino - ou objetivo principal, o Rio Grande do Sul e era predominantemente constituída de homens, solteiros e pais de família desacompanhados, que vislumbravam apenas a chegada ao Brasil e a inserção no mercado laboral (UEBEL; RÜCKERT, 2018, p. 100).

A segunda onda, que veio depois de 2013, já tem como destino o Sul do Brasil. Os imigrantes também têm um perfil diferente da primeira e incluem mulheres, pessoas com mais idade e crianças, com níveis de escolaridade diversas. Eles chegaram ao Brasil por redes de contatos já estabelecidas pelos imigrantes da primeira geração.

Esse processo pode ser caracterizado como um boom imigratório devido às rotas já estarem estabelecidas, aos agenciamentos e à pontualidade do evento (KELLOG, 1998; ROCHA-TRINDADE, 1995 apud UBEL; RÜCKERT, 2018). Quanto à continuidade desta imigração, Ubel e 
Rückert (2018) apontam que, em médio e longo prazo, os fluxos de imigração podem entrar em declínio, porém, em curto prazo, os processos imigratórios continuarão em crescimento. Isso deve-se ao fato das condições socioeconômicas do Haiti ainda serem inferiores às do Rio Grande do Sul, motivo pelo qual ainda é vantajoso tentar a vida fora de seu país de origem.

Quanto ao perfil demográfico dos sujeitos, que delimita idade, gênero e estado civil, foi possível traçar algumas das características dos estudantes que frequentam o curso. A idade dos sujeitos varia entre 15 e 36 anos, sendo a maioria adultos, com mais de 26 anos. O Gráfico 02 mostra a variação de idade dos participantes.

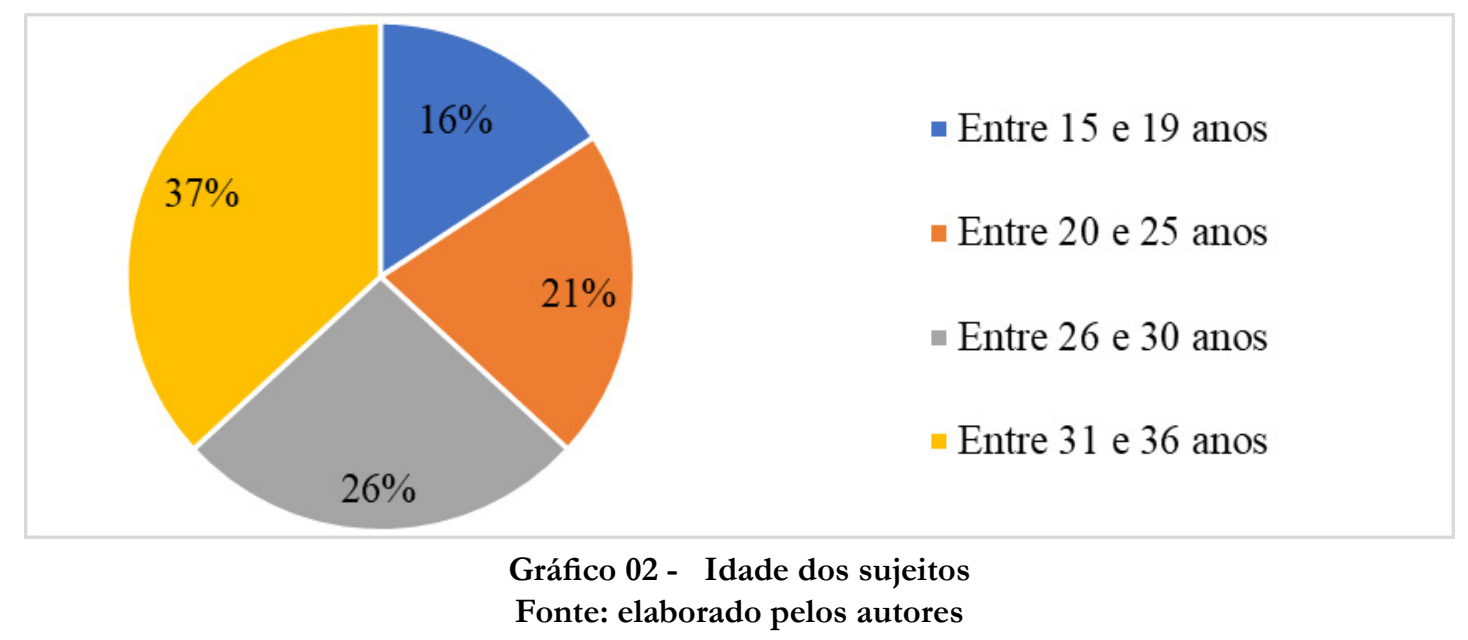

A menor ocorrência foi de 16\%, relativa aos sujeitos que têm entre 15 e 19 anos. Os sujeitos com idades entre 20 e 25 anos correspondem a $21 \%$ das respostas, seguida pelos que têm entre 26 e 30 anos, com 26\%. O maior grupo tem entre 31 e 36 anos, constituindo 37\% dos sujeitos, ou seja, são adultos jovens. Esses dados, ao serem confrontados com os elencados por Zamberlan et. al. (2014), que trazem dados levantados pelo Núcleo de Pesquisa do Cibai Migrações, entre outubro de 2013 e abril de 2014, mostram que não houve diferença na característica deste público nos últimos cinco anos. Afirmam os autores (2014) que a faixa etária dos imigrantes varia entre 25 e 43 anos, correspondendo a 89\% dos entrevistados, que é também a idade que envolve a maioria dos participantes do Curso. Para eles, a faixa etária dos imigrantes contribui para a sua contratação pelas empresas brasileiras. De fato, trata-se de adultos jovens, e que, pela idade, já estavam inseridos no mercado de trabalho antes de emigrarem, possuindo experiência em alguma área ou tendo uma profissão já consolidada.

Quanto ao gênero dos sujeitos, 68\% deles são homens e 26\% são mulheres; 5\% dos alunos não responderam à pergunta. O sexo masculino também é o predominante nas pesquisas de Uebel (2015), e nas pesquisas de Zamberlan et. al. (2014), citadas anteriormente.

No que tange ao estado civil dos sujeitos pesquisados, a maioria deles são solteiros, constituindo $52 \%$ dos pesquisados. A quantidade de casados, separados ou divorciados e que apenas vivem juntos é a mesma, 16\% das ocorrências para cada grupo. Nenhum respondente afirmou ser viúvo(a). Quanto a essa característica, a pesquisa de Zamberlan et. al. (2014) traz dados diferentes, pois informa que há mais imigrantes casados do que solteiros, sendo 47,6\% e 41,7\%, respectivamente. Em seguida, estão os que vivem juntos, 7,2\%, e, por fim, os separados ou viúvos, 1,2\%. Isso revela que no IFRS-Campus Bento Gonçalves, há um predomínio de adultos jovens que buscam 
primeiro ingressar no mercado de trabalho e estabilizar-se financeiramente para, em seguida, trazer a família do Haiti ou estabelecer novas relações aqui no país, com pessoas da mesma nacionalidade ou com brasileiros. Dentre os informantes, apenas um deles estava se relacionando com uma brasileira, a qual conheceu no local de trabalho.

Em relação à paternidade, a maioria dos alunos afirmou não ter filhos, correspondendo a $74 \%$ das respostas. Os que têm filhos representam $26 \%$ dos sujeitos e, deste último grupo, $67 \%$ não estão com os filhos no Brasil, ao contrário dos $17 \%$ que os trouxeram no processo de imigração. Nessa questão, 20\% não responderam. Zamberlan et. al. (2014) afirmam que, no processo imigratório, geralmente, os pais vêm antes a fim de trabalharem, para sustentar os familiares que ficam no Haiti, enviando dinheiro a eles, motivo pelo qual os filhos não emigram para o Brasil num primeiro momento.

Em relação à escolaridade, os sujeitos pesquisados apresentam uma formação escolar bastante heterogênea, que vai do Ensino Fundamental ao Ensino Superior, conforme mostra o Gráfico 03.

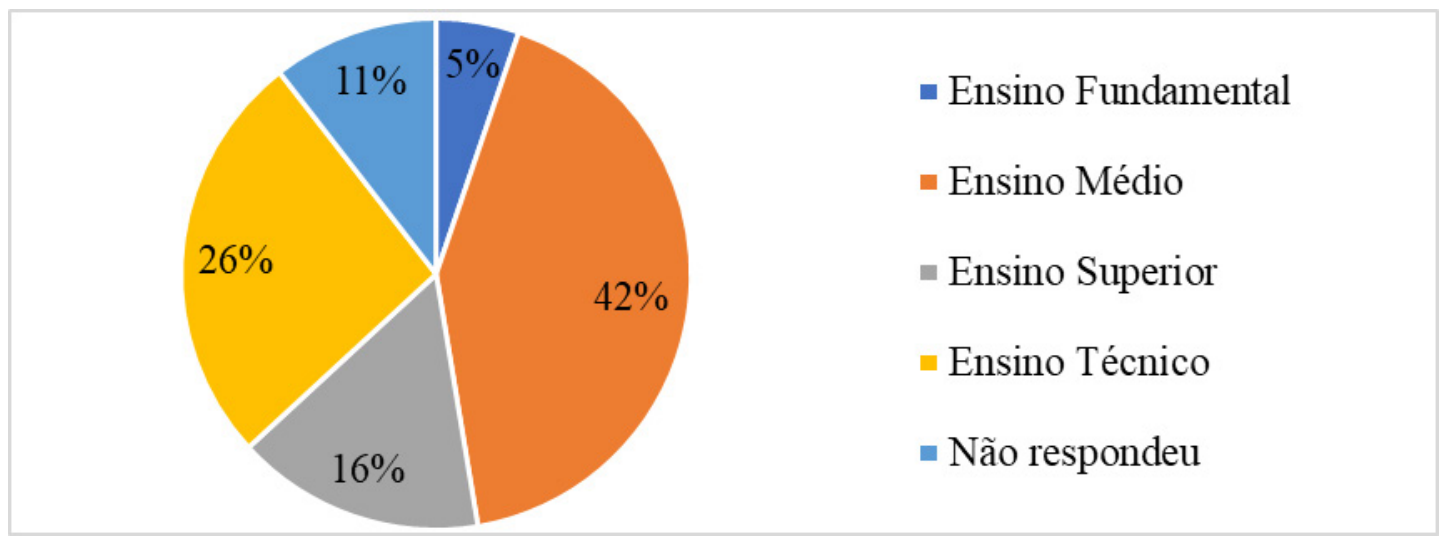

Gráfico 03 - Nível de escolaridade

Fonte: elaborado pelos autores

O Gráfico 03 indica que 42\% dos alunos concluíram o Ensino Médio, 26\% realizaram Cursos Técnicos, 16\% possuem ou estavam cursando o Ensino Superior, 5\% possuem apenas Ensino Fundamental e 11\% dos sujeitos não responderam à questão. Os níveis de escolaridade apresentados por Zamberlan et. al. (2014), são semelhantes aos averiguados por nós, sendo que a pesquisa exposta pelos autores indica que: 26\% têm Ensino Fundamental, 23,8\% têm Ensino Médio, 23,8\% têm Ensino Superior incompleto e 17,8\% têm Ensino Superior completo.

É interessante observar que o nível de escolaridade daqueles imigrantes é superior à média dos brasileiros, pois de acordo com o Instituto Brasileiro de Geografia e Estatística (IBGE), nos dados publicados em 2017, 51\% dos brasileiros com mais de 25 anos concluíram apenas o Ensino Fundamental. Contudo, mesmo com um nível de escolaridade maior, os imigrantes continuam ocupando postos inferiores no mercado de trabalho, sendo que a grande maioria ocupa cargos de auxiliar de produção, auxiliar de limpeza e cozinha e auxiliar de pedreiro, como se vê na sequência.

No que tange ao mundo do trabalho, a maioria dos sujeitos pesquisados estão trabalhando no momento, correspondendo a 79\% deles. As áreas de trabalho variam, conforme o Gráfico 04: 


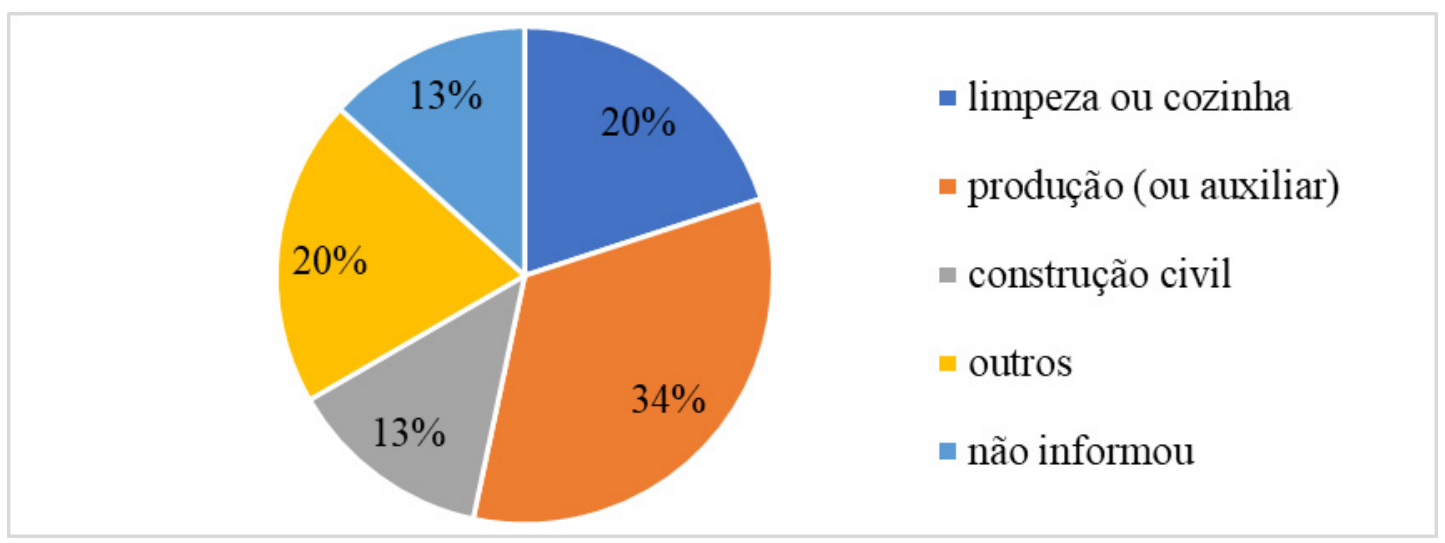

Gráfico 04 - Área de atuação

Fonte: elaborado pelos autores

Como mostra o Gráfico $04,34 \%$ dos alunos trabalham no setor da produção em indústrias da região, 20\% trabalham com limpeza ou como auxiliares de cozinha, 13\% na construção civil, $20 \%$ em outras áreas, que envolvem a indústria alimentícia, por exemplo, e 13\% não informaram a área da atuação. O setor frigorífico é o que mais emprega imigrantes haitianos na Serra Gaúcha. Dentre todos os sujeitos, $89 \%$ dizem ter carteira de trabalho, e todos possuem o documento assinado pelo empregador, o que demonstra estarem formalmente inseridos no mercado de trabalho, podendo acessar direitos trabalhistas.

Ao serem perguntados se gostam do seu trabalho no Brasil, 67\% disseram gostar da atividade que realizam. Outros 33\% disseram que não gostam, principalmente devido ao fato de não trabalharem na profissão que exerciam no Haiti e de considerarem que o salário recebido é pouco. Quanto ao salário, $80 \%$ recebem apenas um salário mínimo por mês, 13\% recebem até dois salários mínimos e 7\% não responderam. Mesmo tendo uma renda baixa, a maioria dos alunos afirmou que, além de destinar seu salário às contas mensais como aluguel, água, luz e comida, envia dinheiro para o Haiti, para ajudar os familiares que ainda estão lá, como cônjuges e filhos, pais e irmãos.

Além da carteira de trabalho, outros documentos expedidos pelo governo brasileiro são fundamentais para os imigrantes conseguirem iniciar uma nova vida no Brasil, como o Cadastro de Pessoa Física (CPF), Registro Nacional de Estrangeiro (RNE), o cartão do Sistema Único de Saúde (SUS) e a Carteira de Vacinação. A maioria dos sujeitos afirmou possuir todos esses documentos: 95\% deles possuem CPF, 84\% possuem RNE, 95\% possuem o cartão do SUS, e 79\% possuem carteira de vacinação. A partir desses documentos eles podem abrir contas em bancos, fazer compras parceladas, alugar uma residência, acessar serviços de saúde e educação, entre outros.

A religião constitui um fator relevante para a manutenção da identidade do grupo, porque os imigrantes têm na religião uma maneira de fortalecer e manter vínculos entre si. A maioria dos alunos do Curso de Extensão do IFRS-Campus Bento Gonçalves, 84\%, afirmaram frequentar alguma igreja ou religião, e as duas mais citadas foram a Igreja Protestante e a Igreja Evangélica, que correspondem, respectivamente, a $41 \%$ e $35 \%$ das respostas fornecidas pelos pesquisados. Há imigrantes que participam de outras igrejas, como a Católica (6\%) e a Adventista (6\%). Contudo, 12\% dos que afirmaram ter alguma igreja ou religião, não responderam qual frequentam. Percebe-se que além de promover a socialização entre os membros do próprio grupo, a igreja torna-se um local propício para os haitianos se integrarem à nova sociedade, uma vez que podem aproveitar o momento das 
celebrações ou cultos para interagir com brasileiros que praticam a mesma religião. Talvez, por isso, a igreja seja um dos poucos lugares, além do local de trabalho, em que os imigrantes haitianos compartilham com os brasileiros alguma troca cultural. Percebe-se uma frequência assídua dos imigrantes à igreja, pois os que a frequentam o fazem todos os finais de semana, especialmente aos domingos, o que se torna para eles, além de uma atividade de prática da religião, também uma forma de lazer e de agregação social.

Em relação à permanência no Brasil, a maioria dos sujeitos pesquisados não pretende continuar no país, mas sim regressar um dia para o Haiti ou então ir para outro país. É o que mostra o Gráfico 05:

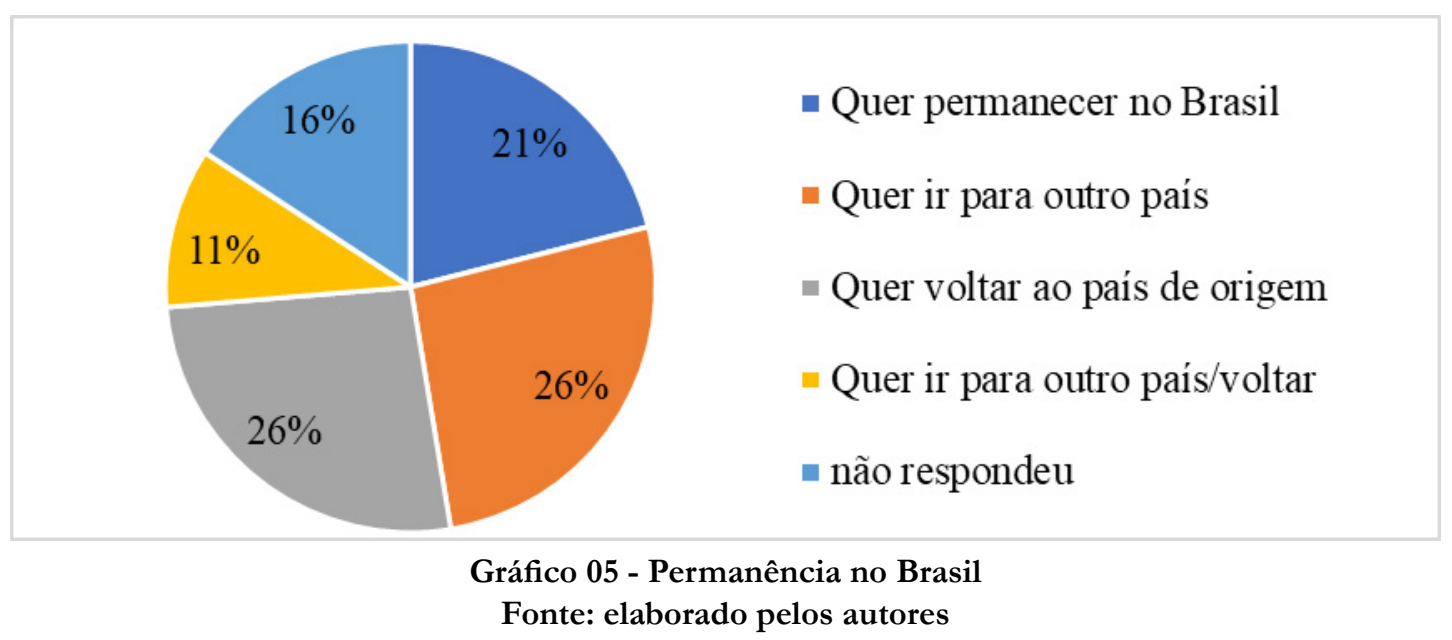

A quantidade de haitianos que querem retornar ao país de origem ou que querem ir para outro país é a mesma, $26 \%$ das respostas em cada caso; $11 \%$ consideram ambas as possibilidades, querem voltar para o Haiti ou então ir para outro lugar. Dentre os países que os imigrantes desejam ter como destino, foram citados o Canadá, os Estados Unidos e a França. Apenas 21\% querem permanecer no Brasil e 16\% não responderam à questão. Caberia investigar melhor os motivos que levam os sujeitos pesquisados a não quererem permanecer no Brasil. Uma das hipóteses seria o preconceito que muitos relataram sofrer em respostas como: "Eu não gosto do Rio Grande do Sul porque todas as pessoas aqui são racistas com os haitianos" e "Eu não gosto do jeito que as pessoas nos tratam aqui" ou o fato de não conseguirem trabalhar na profissão que exerciam no Haiti, como: "Aqui é frio, difícil achar uma boa casa para morar, difícil a gente trabalhar no que a gente estudou."

Em relação ao Curso de Extensão, 84\% dos participantes afirmaram que as aulas de português contribuíram para a comunicação e interação com os brasileiros, $89 \%$ acreditam que o Curso ajudou a resolver questões do dia a dia, 68\% dizem que aprender o idioma os ajudou a conseguir um emprego; e 85\% consideram que o Curso contribuiu para eles integrarem-se à sociedade.

\section{Considerações finais}

A partir dos dados obtidos, é possível traçar o perfil dos imigrantes que frequentam o Curso de Extensão no IFRS-Campus Bento Gonçalves. De maneira geral, pode-se dizer que os participantes são imigrantes que chegaram há menos de 4 anos no Brasil, do sexo masculino, adultos, solteiros e sem filhos. Quanto à escolaridade, possuem Ensino Médio Completo. Exercem atividade remunerada com carteira assinada e recebem, em média, um salário mínimo por mês. Frequentam igrejas Evangélicas ou Protestantes e ainda esperam poder retornar ao país de origem. 
Em relação à aprendizagem da língua portuguesa, os alunos afirmaram que o Curso de Extensão do IFRS - Campus Bento Gonçalves contribuiu para melhorar a comunicação e para a interação deles com os falantes nativos, de modo que os auxiliou a resolver questões práticas do cotidiano, conseguir um emprego e integrar-se à sociedade.

Percebe-se, assim, que o aprendizado da língua portuguesa é o primeiro passo para a efetiva inserção social desses sujeitos, para a construção da cidadania e para a reelaboração da própria identidade. Isso indica que a abordagem teórica para o ensino e a aprendizagem da língua portuguesa não pode conceber a língua desvinculada do contexto de uso, isto é, a língua não é apenas um sistema fixo e imutável de regras, mas sim prática social, cuja existência e funcionalidade depende de seus usuários, ou seja, dos sujeitos que falam, que escrevem e que se comunicam em dada língua.

Pode-se afirmar, portanto, que o Curso de Extensão de Língua Portuguesa para imigrantes e refugiados, fundamentado na concepção de língua de acolhimento, em que a metodologia está intrinsecamente vinculada ao contexto de uso, priorizando as reais necessidades do grupo, com ênfase para as competências linguísticas necessárias a fim de que os sujeitos possam enfrentar as mais diversas situações cotidianas de interação social, vem contribuindo para a integração dos imigrantes haitianos à sociedade brasileira, desenvolvendo ainda um sentimento de pertença à Instituição e valorização dos imigrantes enquanto cidadãos.

\section{REFERÊNCIAS}

AMADO, R. S. O ensino de português como língua de acolhimento para refugiado. Revista SIPLE - Sociedade Internacional de Português Língua Estrangeira, v. 7, 2014. Disponível em http://bit.ly/2ZzK7EQ. Acesso em 02/07/2019.

BENVENISTE, E. Problemas de Linguística Geral. São Paulo: Ed. Nacional; Ed. da Universidade de São Paulo, 1976. BRASIL, 1997. Lei no 9.474, de 22 de julho de 1997. Define mecanismos para a implementação do Estatuto dos Refugiados de 1951, e determina outras providências. Disponível em http://bit.ly/371QE90. Acesso em 04/06/2019. GROSSO, M. J. R. Língua de acolhimento, língua de interação. Horizontes de Linguística Aplicada, v. 9, n. 2, 2010, p. 61-77. Disponível em http://bit.ly/2F0LhzM. Acesso em 15/05/2019.

IBGE, 2017. PNAD Contínua 2016: 51\% da população com 25 anos ou mais do Brasil possuíam no máximo o ensino fundamental completo. 2017. Disponível em http://bit.ly/37lr1VC. Acesso em 19/09/2019.

POLÍCIA FEDERAL. Ministério da Justiça e Segurança Pública. Naturalização. Disponível em http://bit. ly/36cB6UM. Acesso em 26/09/2019.

SÃO BERNARDO, Mirelle Amaral de. Português como língua de acolhimento: um estudo com imigrantes e pessoas em situação de refúgio no Brasil. 2016. 206 f. Tese (Doutorado) - Programa de Pós-Graduação em Linguística, UFSCar: São Carlos, 2016. Disponível em http://bit.ly/2Q7dDi2. Acesso em 12/06/2019.

STERN, H. H. Fundamental Concepts of Language Teaching. Oxford: Oxford University Press, 1983.

UEBEL, R. R. G.; RÜCKERT, A. A.. Haitianos no Rio Grande do Sul: panorama e perfil do fenômeno imigratório contemporâneo. Periplos: GT CLASCO - Migración Sur-Sur, Brasília, v. 01, n. 01, p. 92 - 110, 2018.

UEBEL, R. R. G. Análise do perfil socioespacial das migrações internacionais para o Rio Grande do Sul no início do século XXI: redes, atores e cenários da imigração haitiana e senegalesa. 2015. 248 f. Dissertação de mestrado (Mestrado em Geografia) - Instituto de Geociências, Universidade Federal do Rio Grande do Sul, Porto Alegre, 2015. Disponível em http://bit.ly/2SCAgMZ. Acesso em 10/05/2019.

ZAMBERLAN, J. [et. al]. Os novos rostos da imigração no Brasil: haitianos no Rio Grande do Sul. Porto Alegre: Solidus, 2014.

Recebido em 29/9/2019 Aceito em 20/11/2019 